\title{
OS MOVIMENTOS SINDICAIS E CORPORATIVOS COMO ATORES DA DEMOCRACIA
}

\author{
Francisco de Sousa Andrade
}

Resumo: O artigo aborda as nuances do surgimento do sindicalismo no Brasil, salienta as lutas travadas por reconhecimento de direitos, referencia o conjunto de suas conquistas corporativas e trabalhistas, menciona as disputas entre as correntes políticas por hegemonia e ressalta as contribuições desses movimentos para a consolidação da democracia.

Palavras-chave: sindicalismo; trabalhadores; participação; democracia; greves.

\begin{abstract}
The article discusses the aspects of the rise of unionism in Brazil, highlights the struggles waged for recognition of rights, the reference number of its corporate achievements and labor, given the disputes between the current policies of hegemony and highlights the contributions of these movements to the consolidation of democracy.
\end{abstract}

Keywords: unionism; workers; participation; democracy; strikes.

1 Origens do sindicalismo brasileiro e histórico das lutas, conquistas e correntes sindicais até a Era Vargas

A história da construção das organizações sindicais no Brasil remonta a fins do século XIX, período em que já se registraram diversas manifestações de protesto, ainda que quase absolutamente desprovidas de um caráter político e orgânico mais elaborado. Segundo o relato de Marcelo Badaró Mattos (2001), assistiu-se na cidade do Rio de Janeiro, durante a segunda metade do século XIX, a

Pós-graduado em Instituições e Processos Políticos do Legislativo pelo Centro de Formação, Treinamento e Aperfeiçoamento da Câmara dos Deputados, 2007. francisco.andrade@ camara.gov.br 
uma transformação rápida e profunda no que se refere ao chamado "mundo do trabalho", situando a greve dos tipógrafos de 1858, como fato bastante significativo daquele início de organização e de lutas classistas.

Se esta foi a primeira greve ou não de trabalhadores livres ou assalariados no Brasil, isso é algo difícil de se comprovar, dadas as dificuldades historiográficas e, sobretudo, ao atraso cultural que caracterizou o país por séculos. Contudo encontramos dados e relatos, conforme Giovane Alves, em "A História do Sindicalismo no Brasil” (1998), que dão conta de uma greve realizada ainda em 1720, no Porto de Salvador, na Bahia, à época o maior das Américas.

Neste artigo o que se deseja, e até como forma de reconhecimento, é pontuar os momentos e as conquistas que os trabalhadores marcaram e obtiveram, no curso do processo tardio de industrialização brasileira, em jornadas as mais intensas e ásperas de lutas, contra patrões e governos, por reconhecimento de direitos elementares e pela conquista da cidadania política. Assinala-se, assim, as contribuições que, por intermédio de suas organizações representativas, de fato deram, em muitas oportunidades, para a construção da democracia no Brasil.

Do ponto de vista da sociologia do trabalho urbano e industrial, enquanto a Europa experimentava as agitações sociais e culturais no século XVIII, em face das transformações desencadeadas desde o início da revolução industrial na Inglaterra, ainda no século XVII, e impulsionadas talvez ideologicamente a partir dos acontecimentos decorrentes da Revolução Francesa, iniciada em 1789, o Brasil ainda se valia de relações de trabalho escravo. Sendo o último dos países no continente americano a abolir a escravatura, o país e suas elites dominantes restam como protagonistas de um atraso em quase todos os campos, cujo custo social ainda hoje se faz refletir e permeia de modo bastante negativo o processo de desenvolvimento.

É fato que as lutas e turbulências verificadas no período pré-republicano, ou antes ainda, nos movimentos pela independência - ainda que muitos deles conduzidos pelas elites -nos legaram a raiz primeira de uma perspectiva cívico/organizativa, aqui incluídas as organizações secretas, os maçons, os clubes republicanos. Já do ponto de vista da massa de homens e mulheres que se pretendiam livres, mas despossuídos material e, talvez espiritualmente, não se pode deixar de registrar os episódios que a historiografia oficial não fez com a devida precisão, como a história do beato Antônio Conselheiro, no sertão baiano e, no outro extremo geográfico do país, a chamado "guerra do Contestado", ocorrida nas fronteiras de Santa Catarina, como exemplos primeiros de lutas de libertação, se deles se abstraírem os aspectos de manipulação político/religiosa.

Mas é, sem dúvida, aos imigrantes europeus, especialmente aos italianos e espanhóis, a quem devemos primeiro reconhecer o saldo contributivo de ousadia, por terem trazido, além da força de trabalho, seus sonhos e experiências. Eles aqui chegaram "contaminados" pelas lutas 
contra a exploração do trabalho brutalizado em seus países de origem e por condições de vida mais humanas e dignas.

As primeiras greves de que se tem notícia, conforme já mencionado, datam ainda de fins do século XIX, contudo, afora a "aventura" grevista dos tipógrafos do Rio de Janeiro de 1858, movimentos organizados com caráter de classe e de reivindicações mais definidas e específicas somente vieram a ocorrer, de modo sistemático, por volta de 1906, ano da realização do I Congresso Operário Brasileiro (C.O.B.). Já em 1907, São Paulo foi paralisada por uma manifestação iniciada pelos trabalhadores da construção civil, da indústria de alimentos e metalúrgicos, que acabou atingindo outras cidades do estado, como Santos, Ribeirão Preto e Campinas. Todos esses movimentos reivindicatórios e agitações realizados no início do século XX e até o ano de 1922, foram conduzidos majoritariamente por trabalhadores imigrantes - os anarquistas - de cujas experiências, socialistas e outras correntes vão se utilizar para fundar o Partido Comunista do Brasil - PCB.

Os anos 1920 e 1930 constituem-se no período de definição político-ideológico do sindicalismo no Brasil, o qual se apresenta impregnado do sentimento de mudanças e revoluções mundiais em curso. Em 1917, no compasso dos acontecimentos da revolução operária Russa, uma onde de greves é deflagrada em São Paulo, especialmente nas fábricas têxteis. O movimento teria se espalhado por quase todo o interior do estado e alcançado uma adesão de mais de 50 mil trabalhadores e trabalhadoras e, como resultado, os patrões concederam um aumento imediato de salário e se propuseram a estudar as demais reivindicações. Destaque-se, contudo, que o ganho mais significativo daquele movimento foi o reconhecimento das instâncias sindicais e de representação do operariado.

A superação do anarco-sindicalismo, de fato, nos anos 20, pode ser considerada um marco na organização e na luta dos trabalhadores brasileiros por liberdade e reconhecimento de direitos, haja vista um elenco de conquistas que a seguir são instituídas e logo depois, de forma definitiva, institucionalizadas, com o Decreto-Lei de número 5.452, de $1^{\circ}$ de maio de 1943 - a CLT Consolidação das Leis do Trabalho.

A primeira lei sindical brasileira, surgida no início do século $\mathrm{XX}$, vem a ser o Decreto $\mathrm{n}^{\circ}$ 979, de 6 de janeiro de 1903, feita sob inspiração da igreja católica, que pregava a união do capital e trabalho no campo. O Brasil, afinal, era um país essencialmente agrícola, de acordo com José Carlos Arouca (2007). Esta legislação adotava a forma de organização mista, de trabalhadores e empregadores rurais, para o estudo, custeio e defesa de seus interesses e representava muito mais uma corporação cooperativa do que sindical, na visão do referido autor.

Seguiu-se o Decreto n ${ }^{\circ} 1.637$, de 5 de janeiro de 1907, com a mesma origem e natureza, 
contudo este já buscava contemplar o interesse de todos os trabalhadores, inclusive dos profissionais liberais, mas sem alterar o âmbito de representação das duas classes antagônicas, às quais atribuía, quando constituídas,

com o espírito de harmonia, como sejam os ligados por conselhos permanentes de conciliação e arbitragem, destinadas a dirimir as divergências e contestações entre o capital e o trabalho, feição de 'representantes legais da classe integral dos homens do trabalho', podendo como tais, 'ser consultados em todos os assuntos da profissão' (AROUCA,2007).

Disso é possível se extrair as bases filosóficas em que as primeiras leis sindicais foram instituídas no Brasil, originadas, portanto de um ambiente social dualista e politicamente bastante confuso. Com o calor das efervescências culturais e políticas iniciadas em 1922, da Semana de Arte Moderna, da fundação do Partido Comunista, entre outros, vai-se verificar um salto qualitativo na organização sindical brasileira.

De fato, as agitações sociais, as lutas e as jornadas de greves agora desencadeadas denotavam um outro aspecto de organização, em que o sentimento de pertencimento de classe dava o tom. Com esta perspectiva classista e objetiva, agora os trabalhadores pressionavam patrões e o governo no sentido do reconhecimento de direitos e de melhores condições de vida. Assim, em 1916, é aprovado o Código Civil. Em 1920, é criada uma Comissão Especial de Legislação Social, com a função de analisar toda e qualquer iniciativa legislativa na área trabalhista. Em 1923, são instituídas as Caixas de Aposentadorias e Pensões, sendo que a lei que as criou é considerada a primeira lei de previdência social no Brasil, também conhecida como Lei Elói Chaves. Ainda em 1923, é criado o Conselho Nacional do Trabalho. Entre os anos 1925 e 1927, são votadas diversas leis de proteção social, entre as quais, as que regulamentam as férias e o trabalho de menores. Em 1931, é instituída a Lei Sindical (Decreto 19.770), que cria os pilares do sindicalismo oficial no Brasil. Em 1939, é criada a Justiça do Trabalho e assinado o Decreto-lei $\mathrm{n}^{\circ}$ 1402, que disciplina o funcionamento dos sindicatos (enquadramento sindical), como órgãos de colaboração com o Estado. Em 1940, são regulamentados os direitos trabalhistas dos trabalhadores urbanos: férias

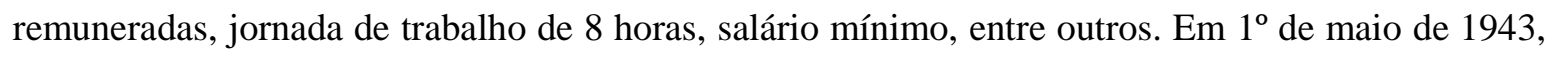
é assinado o Decreto-lei n ${ }^{\circ} 5.452$, regulamentando a Consolidação das Leis do Trabalho - CLT.

Desse período resulta um acúmulo sociológico instigante: a difusão ideológica de organizações sócio-corporativas por meio das quais, numa ponta, reivindica-se autonomia e liberdade de ação, e, na outra, aceita-se, como se num conluio, que seja delegada ao Estado a prerrogativa e os limites dessa liberdade, num comportamento que, conforme Boito Júnior (1991), será o elemento definitivo de atrelamento dos sindicatos ao Estado.

Vale a pena refletir, a esse respeito, sobre as lições oferecidas por Antônio Gramsci, 
Os movimentos sindicais e corporativos como atores da democracia

descritas por Carlos Nelson Coutinho (1999), quando trata do Partido como "intelectual orgânico":

Lênin, em o 'O que fazer?' menciona os elementos básicos universais, da sua concepção de partido. Entre tais elementos destaca-se sua compreensão de que 'a tarefa básica do Partido Operário, do Partido da Revolução Socialista, é a de contribuir para superar na classe operária uma consciência puramente tradiunista, sindicalista'; isso implica fornecer os elementos teóricos e organizativos para que essa consciência possa se elevar ao nível de consciência de classe. " (COUTINHO, 1999, p. 169)

É, portanto, a partir desse longo ensaio corporativo-ideológico, desse recorte de acúmulos sócio-reivindicatórios, dessa profusão libertária-coletivista, de bandeiras e movimentos difusos e, às vezes, ambivalentes, gerados e substanciados na emblemática Era Vargas, que se vão definir as bases sociológicas - nacionalistas-conservadoras, socialistas-reformadores, "revolucionários", etc. do protagonismo sindical e do associacionismo de classe no Brasil.

A propósito, a recorrência às origens da formação sindical no Brasil, pode vir a explicar, com elementos mais conclusivos, a atual fase do nosso sindicalismo, que em mais de cem anos de história parece encontrar-se estacionado, entre as conquistas que, de fato, alcançou, as inegáveis contribuições que com ousadia ofereceu para a perspectiva de consolidação da democracia e o deslumbramento de, na fase atual, em sua grande maioria, considerar-se parte importante do poder do Estado.

\section{Participação dos sindicatos nas lutas contra a ditadura militar de 1964 e pela Constituinte de 1987/1988}

Desde as primeiras associações profissionais até se consolidarem como instâncias de representação de classe legitimamente, os sindicatos, por meio de suas lideranças, deram incontestáveis contribuições tanto para o reconhecimento e institucionalização dos direitos trabalhistas, cujo marco temporal e legal é o ano de 1943 (Lei no 5.452, de $1^{\circ}$ de maio), quanto para as lutas nacionalistas e populares dos anos 50 e início dos anos 60.

Impossível não reconhecer que mesmo com a maioria de seus dirigentes cassados e exilados, as entidades sindicais, enquanto estrutura, mantiveram-se de pé no último período ditatorial, como que amealhando a melhor oportunidade para retomar suas lutas. Nesse sentido, não obstante toda a aspereza do regime militar iniciado em 1964, não foram poucas as tentativas de reação empreendidas por algumas lideranças sindicais, ainda antes dos enfrentamentos sindicais ocorridos no ABC paulista em 1978. De acordo com Paulo Aguena (2007), em 1968, eclodiram duas grandes greves, a dos trabalhadores da Siderúrgica Belgo Mineira, em Contagem (MG), movimento que teria se espalhado por outras fábricas, como a da Manesman, SBE e Acesita; e a outra foi a greve de ocupação da Cobrasma Autopeças, em Osasco (SP), que logo se expandiu para 
outras regiões do estado, também na mesma época.

Segundo Márcio Pochman (2007), após o êxito do período nacionalista e dos anos 50, inicia-se a segunda fase do sindicalismo brasileiro, que vai perdurar até a segunda metade da década de 1970, momento em que o modelo corporativista ou de verniz trabalhista e comunista será posto à prova e, logo a seguir sucumbirá, diante das clivagens estratégicas praticadas pelos articuladores e defensores intelectuais de um novo partido político de trabalhadores e, por conseguinte, de um "novo sindicalismo". O pós autoritarismo e populismo da Era Vargas foi seguido pela consolidação nacionalista dos anos 50, momento da construção da base da estrutura nacional desenvolvimentista e industrial, que se iniciara com a criação, em 1941, das grandes fábricas e companhias nacionais (FNM, FNV e CSN). A partir desse momento, o país evoluiria de um modelo concentrador agrário e passaria a edificar as bases econômicas e industriais urbanas e capitalistas. Os trabalhadores tinham como guia político o padrão corporativista anteriormente consolidado.

As correntes sindicais em ação no início dos anos 60, eram, portanto, herdeiras do trabalhismo-corporativista e populista estatal incentivado por Vargas ou da concepção também autoritária, embora pretensamente revolucionária, dos comunistas, que somente a partir de março de 1958, principiaram uma crítica ao modelo centralizado que defendiam, mas ainda demasiado viciados nas práticas sindicais instrumentalizantes e cupulistas. É, pois, possível, que dessas duas vertentes ideológicas tenha vingado o que restou para fazer o renascimento sindical de fins dos anos 70 e início dos anos $80^{1}$.

Seguindo a onda nacional pelo restabelecimento da democracia no início dos anos 80 , a imensa maioria dos dirigentes sindicais, especialmente de entidades de classe média ou de médioassalariados, participou ativamente da campanha das "Diretas Já", em todo o país.

Como grupo de pressão legítimo, os sindicatos a meio de sua consolidação e das lutas economicistas que eram obrigados a travar no grave período inflacionário vivido entre o fim da

1 Conforme pesquisa que realizamos para a consecução da monografia "Os movimentos sindicais e corporativos como atores da democracia" (ANDRADE, 2007), entre os atores mais representativos identificados pelo estudo na formação dos sindicatos, sobressaem-se os anarquistas de origem italiana, principalmente, e a seguir o Partido Comunista Brasileiro PCB, fundado em 1922, instituição que teve sua vida legal ao longo de cerca de 70 anos de existência, por várias vezes interrompida, quando as diversas ditaduras cassavam seus líderes e o mandavam para a clandestinidade. Ao ressaltar a importância da contribuição dos comunistas no curso de todo o período estudado, pretendemos estabelecer um contraponto entre as práticas sindicais vigentes até 1964, momento em que esta corrente política ao lado dos trabalhistas era quase hegemônica no domínio das cúpulas sindicais, e o "novo sindicalismo", modelo orientado por intelectuais nãocomunistas e pela igreja católica, através das CEBs. Questionamos, assim, a tese defendida por alguns intelectuais de que tenha havido de fato um "novo sindicalismo", a despeito de se reconhecer novas atitudes e estratégias de ação sindical, umas até então inéditas, como as greves feitas de dentro das fábricas, por exemplo, antes a busca por uma nova hegemonia sindical, notadamente de visão não-comunista. Defendemos também a tese de que os sindicatos trabalhistas, de fato, surgiram no Brasil do mais veemente conflito de interesses e, por isso mesmo, foram, nas duas primeiras décadas de sua estruturação, instrumentos de luta de classe. Reconhecemos, porém, as contribuições ofertadas pelos trabalhadores ao longo desses cerca de cem anos de história sindical à construção da democracia, além de participar direta e indiretamente para normatizar um código de direitos materiais do trabalho, que já ultrapassa os sessenta e cinco anos de proteção trabalhista. 
ditadura militar até o início dos anos 90, agiram firme para fazer valer os direitos antes conquistados pelos trabalhadores na Constituinte de 1987/1988, ainda que os representantes no parlamento do chamado "novo sindicalismo" - bancada do Partido dos Trabalhadores - tenham se negado a assinar a nova Constituição.

\section{Desafios, Resistência e a necessidade de se reinventar}

Atualmente, diante da globalização, o sindicalismo brasileiro se depara com uma crise conjuntural sem precedentes em sua história. Na verdade, a quebra de paradigmas a partir do momento em que muitos historiadores chamam de revolução tecnológica, ou revolução tecnocientífica, da introdução nos meios de produção e nos demais setores da economia de tecnologias de ponta, da informatização, do uso da robótica, etc, promoveu mudanças repentinas e espetaculares nas relações de trabalho, causando desemprego em massa e colocando em risco a sobrevivência de milhares e milhares de trabalhadores, cuja formação era no geral inadequada e insuficiente para enfrentar os desafios desses novos tempos.

Por sua vez, muitas lideranças sindicais ficaram sem as suas antigas referências de atuação e de visão de mundo, uma vez que, em sua imensa maioria, eram oriundos de partidos de esquerda ou formados numa concepção político-ideológica agora defasada em vista das bruscas transformações políticas de fins do século XX, como o esfacelamento da ex-União Soviética, a desintegração e as lutas nacionalistas nos países até então denominados como "do socialismo real", fatos ocorridos sobretudo após a queda do muro de Berlim, em novembro de 1989.

Enquanto nos países da União Européia e nos Estados Unidos os sindicatos buscavam alternativas para enfrentar a conjuntura adversa, realizando fusões, por exemplo, no Brasil, os representantes dos trabalhadores encontravam-se atônitos diante da recessão econômica e da necessidade de defesa do emprego de seus representados. As novas estratégias empresariais de competitividade extremada, de enxugamento do quadro de pessoal, da chamada reestruturação, levaram os sindicatos em geral para a defensiva. Na verdade, foram forçados a uma quase inatividade política, o que refletiu em perdas consideráveis no nível de sindicalização.

Clássicas e antigas bandeiras de luta, portanto, foram colocadas de lado pelos sindicatos, ante à inércia imposta pela nova conjuntura econômica. Enquanto isso, as principais correntes sindicais não se dispõem a transigir para uma renovação de valores e para uma nova estratégia de ação coletiva. Ao contrário, persistem numa prática política viciada e a cada dia mais dividida, devido o engalfinhamento político histórico reinante no interior do movimento, em função das rotineiras disputas pela hegemonia das máquinas sindicais. E diante desse cenário, os trabalhadores foram ficando mais e mais distantes e descrentes de suas entidades de classe, o que resultou em 
enorme perda de representatividade e, muitas vezes, até no questionamento da sua necessidade.

Os militantes e sindicalistas, de modo geral, se utilizaram - e assim ainda se comportam das máquinas sindicais como mero espaço de incremento de carreiras políticas, em detrimento de uma exigida reflexão e oxigenação nos métodos de ação. Desse modo, utilizam o dinheiro do imposto sindical para fins outros, (patrocínio de campanhas políticas e auto-promoção de alguns de seus dirigentes), sem o menor pudor, haja vista que não são fiscalizados pelo poder público, como deveriam.

Do segundo semestre de 2007 para cá, foram fundadas mais 3 ou 4 novas centrais sindicais, na perspectiva de embolsarem uma fatia dos 10 por cento do imposto sindical que agora têm direito, e igualmente livre de qualquer fiscalização.

Eis o quadro em que se encontram os herdeiros de uma tradição de atores sociais que num passado recente, muito contribuiu, não apenas nas suas lutas legítimas corporativas, mas também para o aprofundamento e a consolidação da democracia em nosso país.

Foi e pode-se afirmar que ainda é inquestionável a importância dos sindicatos de trabalhadores no Brasil, com o poder de pressão que ainda detêm, para agirem junto aos governos e no Congresso Nacional. Isso se recuperarem a unidade e legitimidade. O contexto atual, de desemprego, subemprego, precarização de mão-de-obra formal, informalidade, terceirização e exigência cada vez maior de melhor qualificação dos empregados, parece exigir uma postura inovadora e sobretudo democratizante das lideranças sindicais e de suas entidades no Brasil. Recuperar o elo perdido da solidariedade de classe, reconstruir um espaço mínimo de ações unitárias entre as diversas facções e centrais, e lutar notadamente pela redução da jornada de trabalho, para geração de novas vagas e para permitir uma vida mais digna aos trabalhadores, são talvez, algumas das bandeiras através das quais pudessem ser retomadas frentes de mobilização, no sentido de restituírem-se a representatividade e a legitimidade de antes.

Por outro lado, as recentes e obtusas ações do conjunto de dirigentes e centrais sindicais, das pressões pouco legitimadas, exercidas junto ao Congresso Nacional e ao governo para manterem o imposto sindical e livrarem-se da fiscalização desses recursos públicos, são mostras arraigadas e estranhamente alienadas, de um passado de histórias tão relevantes que tiveram.

Na visão deste autor, as lutas de classe não acabaram, mas ao contrário, elas se sofisticaram diante do desafio capitalista e globalizante, no sentido de exigir dos representantes, dos interlocutores do mundo do trabalho, outras qualidades, com autonomia e independência políticas, além de uma profunda revisão de métodos de ação e de gestão de suas entidades.

Para serem os atores e protagonistas sociais respeitados como o estudo demonstra que antes foram, as lideranças sindicais de todas as correntes precisam, antes de mais nada, de reinventarem 
seus procedimentos, especialmente no sentido de dar transparência da gestão do dinheiro arrecadado dos trabalhadores, do uso mais adequado das máquinas sindicais em prol de suas categorias e da democratização da gestão sindical. Devem levar em conta a pluralidade e a diversidade de pensamentos existentes no interior de suas bases, de modo a permitir uma necessária renovação nos seus quadros dirigentes, oxigenando lideranças e militantes, para enfrentar os desafios tecnológicos e sócio-econômicos impostos ao mundo do trabalho pela atualidade global.

\section{Referências}

A HISTÓRIA DO SINDICALISMO NO BRASIL. SINTSEF. Disponível em: www.sintet.ufu.br . Acesso em: 21/02/2007

ALVES, Giovane. Reestruturação Produtiva e Crise do Sindicalismo no Brasil. Tese de Doutorado, IFCH/UNICAMP, Campinas, 1998.

ANTUNES, Ricardo. Adeus ao Trabalho?: Ensaio sobre as Metamorfoses e a centralidade do Mundo do Trabalho. Cortez/Unicamp, São Paulo, 1995.

AROUCA, José Carlos. Legislação Sindical: passado, presente e futuro. Disponível em: www.diap.org.br/index.php/integras/6296-legiscao_sindical_passado_presente_e_futuro - Acesso em: 23/05/2007.

BOITO, Júnior Armando. O Sindicalismo de Estado no Brasil - Uma análise crítica da estrutura sindical. Campinas, SP. Editora da Unicamp; São Paulo: Hucitec 1991.

CONSOLIDAÇÃO DAS LEIS DO TRABALHO - CLT 14 Edição (organização de Juarez de Oliveira), série Legislação brasileira - São Paulo: Ed. Saraiva, 1992.

CONSTITUIÇÃO DA REPÚBLICA FEDERATIVA DO BRASIL, 1988, 16ª Edição - Câmara dos Deputados. Coordenação de Publicações - Brasília, 2001.

GREVES Operárias. Wikipédia. A enciclopédia livre Disponível em: wikipedia.org/wiki/Greves operárias. Acesso: 2/07/2007.

MANCUR, Olson. A lógica da ação coletiva - Uma teoria dos grupos sociais e das organizações, São Paulo: Edusp, 1999.

MARX, Karl e ENGELS, Frederico. Manifesto do Partido Comunista, 1848 - São

Paulo: Cortez, 1998.

MATTOS, M.B. Trabalhadores Escravos e livres no Rio de Janeiro da segunda metade do século XIX. Disponível em: www.labhstc.ufsc.br Acessoem 2/072007.

NOGUEIRA, Arnaldo. A Modernização Conservação do Sindicalismo Brasileiro. S. Paulo: Educational Book Publishers, 1998.

POCHMANN, Márcio. SINDEEPRES 15 ANOS A sindicalização no emprego formal terceirizado no Estado de São Paulo. São Paulo: Unicamp, 2007.

RODRIGUES, Leôncio Martins. Destino do Sindicalismo. São Paulo: Edusp, 1999.

SANTOS, Milton. Por uma outra globalização. Rio de Janeiro: Record, 2000. 